\title{
Tomatinase from Fusarium oxysporum f. sp. lycopersici Is Required for Full Virulence on Tomato Plants
}

\author{
Yolanda Pareja-Jaime, M. Isabel G. Roncero, and M. Carmen Ruiz-Roldán \\ Departamento de Genética, Universidad de Córdoba, Edificio Gregor Mendel, Campus de Rabanales, 14071 Córdoba, Spain
}

Submitted 14 January 2008. Accepted 3 March 2008.

\begin{abstract}
Saponin detoxification enzymes from pathogenic fungi are involved in the infection process of their host plants. Fusarium oxysporum f. sp lycopersici, a tomato pathogen, produces the tomatinase enzyme Tom1, which degrades $\alpha$-tomatine to less toxic derivates. To study the role of the tom 1 gene in the virulence of $F$. oxysporum, we performed targeted disruption and overexpression of the gene. The infection process of tomato plants inoculated with transformants constitutively producing Tom1 resulted in an increase of symptom development. By contrast, tomato plants infected with the knockout mutants showed a delay in the disease process, indicating that Tom1, although not essential for pathogenicity, is required for the full virulence of $F$. oxysporum. Total tomatinase activity in the disrupted strains was reduced only $25 \%$, leading to $\beta_{2}$-tomatine as the main hydrolysis product of the saponin in vitro. In silico analysis of the $F$. oxysporum genome revealed the existence of four additional putative tomatinase genes with identities to tomatinases from family 3 of glycosyl hydrolases. These might be responsible for the remaining tomatinase activity in the $\Delta$ tom 1 mutants. Our results indicate that detoxification of $\alpha$-tomatine in $F$. oxysporum is carried out by several tomatinase activities, suggesting the importance of these enzymes during the infection process.
\end{abstract}

Additional keywords: fungal pathogen, saponins.

Plants produce, as a consequence of their normal metabolism, a set of secondary metabolites with antimicrobial properties that have been classified as phytoanticipins (Vanetten et al. 1994). Therefore, plant pathogens must combat these compounds in order to perform a successful interaction. Tomato plants (Lycopersicon esculentum) produce the antifungal compound $\alpha$-tomatine, a steroidal glycoalkaloid consisting of an aglycone moiety (tomatidine) and an oligosaccharide moiety ( $\beta$-lycotetraose) composed of four sugars (one molecule of galactose, one of xylose, and two of glucose), considered to be a saponin. The molecule is present in roots, stems, leaves, and green fruit, reaching concentrations up to $1 \mathrm{mM}$ in some areas (Roddick 1977). Similarly to other saponins, the toxic effect of $\alpha$-tomatine is attributed to its ability to form complexes with the $3 \beta$-hydroxy sterols of the fungal membrane, causing pores and leakage of the cellular content (Keukens et al. 1992, 1995; Roddick 1979).

Fusarium oxysporum f. sp. lycopersici is a soilborne pathogen that causes vascular wilt disease on tomato plants (Di Pietro et al. 2003). During the infection process, the fungus copes with

Corresponding author: Carmen Ruiz-Roldán; Telephone: +34 957218981; Fax: +34 957212072; E-mail: ge2rurom@uco.es inhibitory levels of the saponin. Tomato pathogens are less sensitive to $\alpha$-tomatine than those nonpathogenic on this plant species (Arneson and Durbin 1967a and b; Steel and Drysdale 1988; Suleman et al. 1996); therefore, these microbes must display mechanisms to circumvent the effects of the molecule (Morrissey and Osbourn 1999; Osbourn 1996; Vanetten et al. 2001). Some pathogens tolerate saponins through passive mechanisms such as lacking sterols in their cell membranes, resulting in and inability to cause electrolyte leakage (Arneson and Durbin 1967a and b; Defago and Kern 1983; Keukens et al. 1992). Others produce specific enzymes, collectively designated tomatinases, that remove at least one sugar from the tetrasaccharide moiety, which seems to be sufficient to detoxify the molecule. This is the case of F. oxysporum f. sp. lycopersici, which expresses at least one extracellular protein with tomatinase activity (Ford et al. 1977; Roldan-Arjona et al. 1999). Tomatinases have been identified in other tomato pathogens, such as Septoria lycopersici (Arneson and Durbin 1967a and b; Durbin and Uchytil 1969), Verticillium albo-atrum (Sandrock and VanEtten 1998), Botrytis cinerea (Quidde et al. 1998), F. solani (Lairini and Ruiz-Rubio 1998), or Alternaria solani (Schönbeck and Schlösser 1976); however, they differ in their mechanism of action and seem to belong to different protein families. Whereas tomatinases from $S$. lycopersici and V. alboatrum, both members of family 3 of $\beta$-glycosyl hydrolases, remove the $\beta$-1,2-linked glucose to produce $\beta_{2}$-tomatine (Sandrock and VanEtten 1998), B. cinerea seems to catalyze the hydrolysis of the $\beta$-1,3-xylose to release $\beta_{1}$-tomatine (Quidde et al. 1998). In contrast, tomatinase from A. solani degrades the saponin to tomatidine by releasing the four monosaccharide (Schönbeck and Schlösser 1976). Tomatinase from $F$. oxysporum f. sp. lycopersici, which belongs to family 10 of $\beta$-glycosyl hydrolases, cleaves the $\beta$-1-galactose, releasing the entire oligosaccharide chain and tomatidine (RoldanArjona et al. 1999). Several tomatinases belonging to family 10 of glycosyl hydrolases have been reported in the weak tomato pathogen Gibberrella pulicaris (Weltring et al. 1998) and in the pathogenic bacteria Clavibacter michiganensis subsp. michiganensis (Kaup et al. 2005) and Streptomyces turgidiscabies (Kers et al. 2005). The role of saponinases in fungal pathogenicity to plants remains controversial. Detoxification of saponins has been associated with pathogenicity, although this has been clearly confirmed only for the interaction between Gaeumannomyces graminis var. avenae and oat plants (Bowyer et al. 1995). Targeted disrupted mutants deficient in avenacinase activity from $G$. graminis var. avenae revealed that the enzyme was essential for pathogenicity to oat (Bowyer et al. 1995). Despite this finding, tomatinase deficient mutants from Septoria lycopersici (Martin-Hernandez et al. 2000) and from Colletotrichum coccodes (Sandrock and Vanetten 2001) showed unaltered virulent phenotypes. On the other hand, het- 
erologous expression of the tomatinase gene from $S$. lycopersici in the nontomatinase-producing pathogens Cladosporium fulvum and Nectria haematococca resulted in increased sporulation rates on tomato plants (Melton et al. 1998; Sandrock and Vanetten 2001), thus demonstrating their implication in virulence. It also has been reported that tomatinases might play a role in suppression of fundamental disease resistance processes (Bouarab et al. 2002; Ito et al. 2004; Martin-Hernandez et al. 2000), being present and expressed even in nonpathogens of tomato during symptomless infection of the plant (Ito et al. 2005; Lairini et al. 1997). Recently, in a failed attempt to disrupt the tomatinase gene from $F$. oxysporum f. sp. lycopersici, partially silenced transformants of this gene showed reduced virulence, revealing a possible role of tomatinase from $F$. oxysporum in pathogenicity (Ito et al. 2002).

The aim of this report is to clarify the role of the tomatinase gene toml (Roldan-Arjona et al. 1999) in the pathogenic behavior of $F$. oxysporum f. sp. lycopersici. We have generated fungal strains of $F$. oxysporum f. sp. lycopersici that do not express the Tom 1 enzyme through targeted gene disruption, as well as a strain that constitutively expresses Tom1. Our results indicate that tomatinase contributes to virulence of this fungal species on tomato plants.

\section{RESULTS}

\section{Targeted disruption and overexpression} of the tom 1 gene in the wild-type strain.

To determine the function of the tom 1 gene (Roldan-Arjona et al. 1999), mutants carrying a disrupted copy of the gene were generated by gene replacement. A linear fragment con-
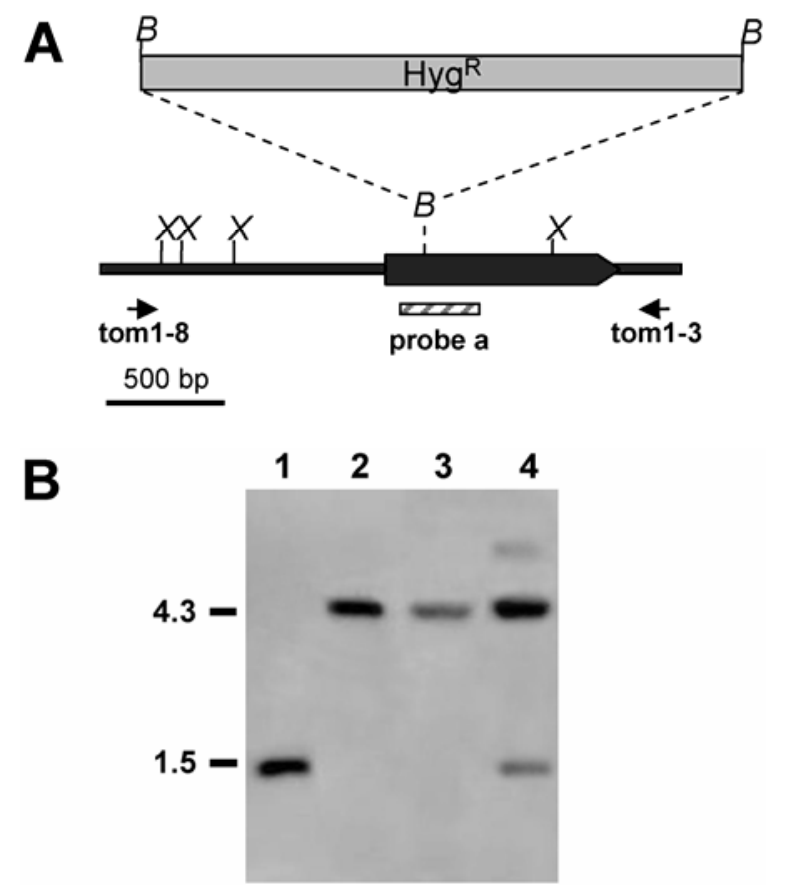

Fig. 1. Targeted disruption of the Fusarium oxysporum tom 1 gene. A, Restriction map of the genomic region and gene disruption vector. The tom 1 coding region is shown as a black arrow indicating the orientation of the open reading frame. Small arrows indicate the primers used for polymerase chain reaction amplification of the gene disruption vector. The hygromycin resistance $\left(\mathrm{Hyg}^{\mathrm{r}}\right)$ cassette is indicated by a gray box. Restriction enzymes are $\mathrm{X}=$ XhoI and B = BamHI. B, Southern analysis of Fusarium strains: lane 1, wild-type strain; lanes 2 and 3, Dtoml\#1 and $\Delta$ toml\#2 transformants; and lane 4, ectopic integration transformant no. 9. DNAs were $X h o I$ digested and hybridized with the indicated probe. Size markers are in kilobases. taining an internal region of the toml allele interrupted by the hygromycin resistance $\left(\mathrm{Hyg}^{\mathrm{r}}\right)$ cassette (Fig. 1A) was introduced into protoplasts of $F$. oxysporum f. sp. lycopersici wild-type strain 4287. Hyg $^{\mathrm{r}}$ selection allowed the isolation of 131 transformants which initially were screened by polymerase chain reaction (PCR) amplification and analysis of the pattern consistent with homologous replacement of the toml gene. According to PCR analysis, only eight transformants showed amplification bands consistent with the disrupted tom 1 allele (named transformants no. 1 to 8) (data not shown). The homologous recombination events in transformants no. 1 and 2 were confirmed by Southern analysis using an internal fragment of the toml coding region as a probe (Fig. 1B, probe a). The wild-type strain showed a $1.5-\mathrm{kb}$ XhoI hybridizing fragment corresponding to the tom 1 allele (Fig. 1B). This fragment was replaced by a 4.3-kb band in transformants that had undergone disruption of the tomatinase gene (Fig. 1B). Transformant \#9 displayed the original $1.5-\mathrm{kb}$ XhoI band and additional hybridizing fragments, indicating ectopic insertions of the disrupted allele (Fig. 1B).

F. oxysporum strains carrying a constitutively overexpressed tom $1^{\mathrm{C}}$ allele were produced by fusing the tom 1 coding region to the Aspergillus nidulans gpdA promoter (PgpdA) (Fig. 2A). The entire construct was amplified by PCR and introduced into protoplasts of the wild-type strain by co-transformation together with the phleomycin resistance $\left(\mathrm{Phleo}^{\mathrm{r}}\right)$ cassette. A number of $\mathrm{Phleo}^{\mathrm{r}}$ transformants were selected, and the presence of the complete $t o m 1^{\mathrm{C}}$ allele was confirmed by Southern analysis using an internal tom 1 gene fragment as a probe (Fig. $2 \mathrm{~B}$, probe $\mathrm{b})$. The presence of the wild-type allele $(2 \mathrm{~kb})$ was detected in the wild-type strain as well as in all the analyzed transformants. One additional hybridizing band was observed in each transformant consistent with the ectopic insertion of the $t o m 1^{\mathrm{C}}$ construct into the genome (Fig. 2B).
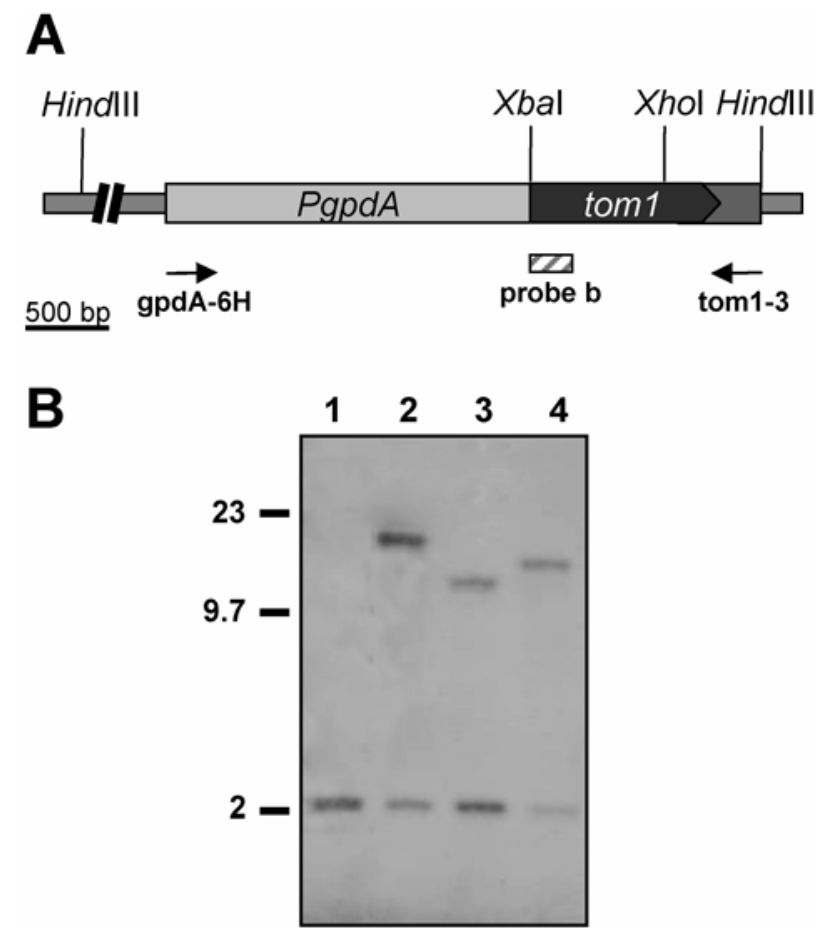

Fig. 2. Overexpression of the tom 1 gene. A, Physical map of the overexpression vector. The tom 1 gene is shown as a black arrow fused to the Aspergillus nidulans gpdA promoter. Small arrows indicate the primers used for polymerase chain reaction amplification. B, Southern analysis of lane 1, the wild-type strain; and lanes 2,3 , and 4, three different $\operatorname{tom} 1^{\mathrm{C}}$ transformants. Genomic DNAs were digested with HindIII and hybridized with the indicated probe. Size markers are in kilobases. 
Northern analysis was used to confirm the absence of tom 1 transcripts in the knockout mutants and its overexpression in the tom $1^{\mathrm{C}}$ strains (Fig. 3). It has been reported that the tom 1 gene is induced by $\alpha$-tomatine (Roldan-Arjona et al. 1999). Total RNA obtained from mycelia of the different strains grown for $3 \mathrm{~h}$ in the absence or presence of $\alpha$-tomatine at 30 $\mu \mathrm{g} \mathrm{ml}{ }^{-1}$ was hybridized to an antisense tom 1 probe amplified with primer tom1-16 (Table 1). The toml transcripts were detected only in the wild-type strain grown in the presence of $\alpha$ tomatine (Fig. 3), whereas no signal was detected in the knockout mutants in any condition. By contrast, in the constitutive tom $1^{\mathrm{C}} \# 1$ transformant, tom 1 transcription was independent of the presence of $\alpha$-tomatine. One transformant harboring an ectopic insertion of the disruption construct showed the same expression pattern as the wild-type strain. These results confirmed that transformants no. 1 and 2 were targeted mutants lacking a functional copy of the tom l gene, whereas transformant tom $1^{\mathrm{C}} \# 1$ constitutively transcribed the tom 1 gene.

\section{Tomatinase activity in $\Delta$ tom 1 and $\operatorname{tom}^{\mathrm{C}}$ transformants.}

The effect of the disruption or the overexpression of the toml gene on total extracellular tomatinase activity from $F$. oxysporum was determined. Total protein was extracted from culture filtrates by acetone precipitation from the different strains grown for $48 \mathrm{~h}$ in liquid CA (casamino acids) in the absence or presence of $\alpha$-tomatine. Tomatinase activity was assayed by visualizing the presence of reducing sugars spectrophotometrically at $525 \mathrm{~nm}$ with the dinitrosalicylic acid reagent (DNS) (Fig. 4). As expected, the wild-type strain showed a significant increase in the levels of tomatinase activity under inducing conditions, whereas no significant activity was observed in the absence of $\alpha$-tomatine. A reduction of approximately $25 \%$ in tomatinase activity was detected in the filtrates of the disrupted mutants $\Delta$ tom $1 \# 1$ and $\Delta$ tom $1 \# 2$ in the presence of $\alpha$-tomatine compared with the wild-type strain. By contrast, high levels of activity were observed in filtrates from the constitutive $t o m 1^{\mathrm{C}}$ transformants independently of the presence of $\alpha$-tomatine in the culture medium.

The degradation products of $\alpha$-tomatine produced by the different strains were analyzed by thin-layer chromatography (TLC) under both inducing and noninducing conditions (Fig. 5). The analysis revealed culture filtrates from the wild-type strain

Table 1. Oligonucleotides used in this study

\begin{tabular}{ll}
\hline Name & \multicolumn{1}{c}{ Sequence $^{\mathbf{a}}$} \\
\hline tom1-X1 & tctagaatgaaggccactatcatcatcg \\
tom1-3 & tggcactggaatgaaagtc \\
tgggttacaggatcctgagataag \\
tom1-5B & gctgacccagacaggctgc \\
tom1-8 & actgagagaggatceggccaagaa \\
tom1-9B & ttcttggccggatcctctctcagt \\
tom1-11X & ctegagctcaagcagtcaaaatccct \\
tom1-12H & aagcttcgacgagttgtgctaccatct \\
tom1-16 & aacatcaagggcttcgctcc \\
tom2-1 & ccacttctgcgacactgcta \\
tom2-2 & ctgtgttcctgttcgtttcc \\
tom3-1 & ctatcattggtcttgccegtt \\
tom3-2 & tgttggaggatactgcgtcta \\
tom4-1 & atcccgtctatccctccc \\
tom4-2 & aagagactccagaatgcgttg \\
tom5-1 & tgtgttggtctcgggtcttt \\
tom5-2 & tagtctcctccatcgcaatac \\
gpdA-6H & aagcttcagttcatgggcgtt \\
gpd-2k & cagcgactggtacctcca \\
trpter-2k & gattacctctaaacaaggtacc \\
act-1 & atgacccagatcgtcttcgag \\
act-2 & gagggaccgcctcgtcgt \\
\hline
\end{tabular}

${ }^{\text {a }}$ Restriction sites introduced in the original sequences are shown in bold. grown in the presence of $\alpha$-tomatine caused the hydrolysis of the saponin and showed the appearance of two degradation products: a major spot corresponding to tomatidine and a minor one, which may correspond to $\beta_{2}$-tomatine. This second spot was the only degradation product obtained from the induced crude extract of the disrupted strains, suggesting that $\alpha$-tomatine was degraded to $\beta_{2}$-tomatine by these mutant extracts, whereas tomatidine was the only product released by crude extracts from the constitutive transformants under either inducing or noninducing conditions, probably because the high amount of the Tom 1 enzyme in these strains favors the degradation of the $\alpha$-tomatine to tomatidine.

\section{Sensitivity of $\Delta$ tom 1 mutants to $\alpha$-tomatine.}

The abilities to grow on agar medium containing $\alpha$-tomatine shown by two targeted mutants, $\Delta$ tom $1 \# 1$ and $\Delta$ tom $1 \# 2$, and by the constitutive tom $1^{\mathrm{C}} \# 1$ transformant, were compared with the wild-type strain (Fig. 6A). The differences were quantified by measuring the colony diameters and the halos surrounding them (Fig. 6B). No differences between strains were observed in the absence of $\alpha$-tomatine. Both the wild-type strain and the tom $1^{\mathrm{C}}$ mutant showed approximately $35 \%$ growth inhibition (GI) on plates containing $0.5 \mathrm{mM} \alpha$-tomatine compared with their growth in its absence (Fig. 6A and C). By contrast, the

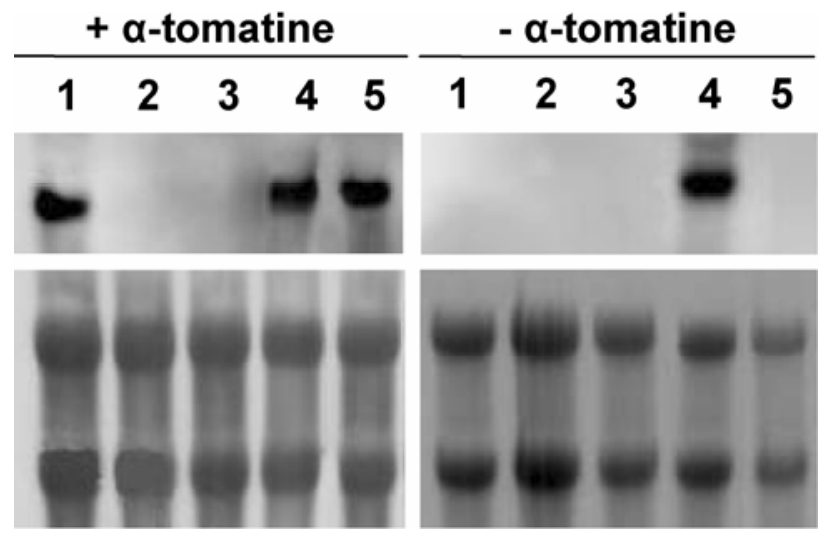

Fig. 3. Expression analysis of the tom 1 gene. Upper panels, Northern analysis of total RNA extracted from mycelia grown in the presence $(+)$ or absence (-) of $\alpha$-tomatine using a tom 1 antisense probe. Lane 1 , wild-type strain; lanes 2 and $3, \Delta$ tom $1 \# 1$ and $\Delta$ tom $1 \# 2$ transformants; lane 4, tom $I^{\mathrm{C}}$ transformant; lane 5, an ectopic integration transformant. The lower panels show RNAs stained with methylene blue.

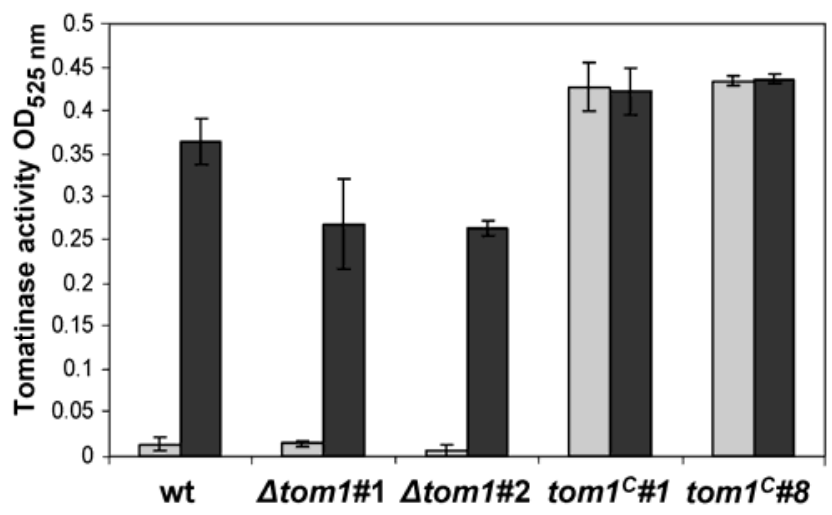

Fig. 4. Total tomatinase activity from Fusarium oxysporum strains, measured using protein extracts from culture medium from the different strains grown in the absence (gray bars) or presence (black bars) of $\alpha$-tomatine. Tomatinase activity is expressed as the absorbance at $525 \mathrm{~nm}$ of the reaction mixture. Each column represents the mean of three independent experiments, and the standard error bars are indicated. 
knockout mutants showed $50 \%$ GI on $0.5 \mathrm{mM} \alpha$-tomatine. The appearance of a translucent halo surrounding the colonies was evidenced when strains were grown in the presence of $\alpha$-tomatine, which might be a consequence of the saponin hydrolysis. The ratio halo/colony diameter was similar in the wild-type strain and the $\Delta$ tom 1 mutants, despite the fact that $\Delta$ toml\#1

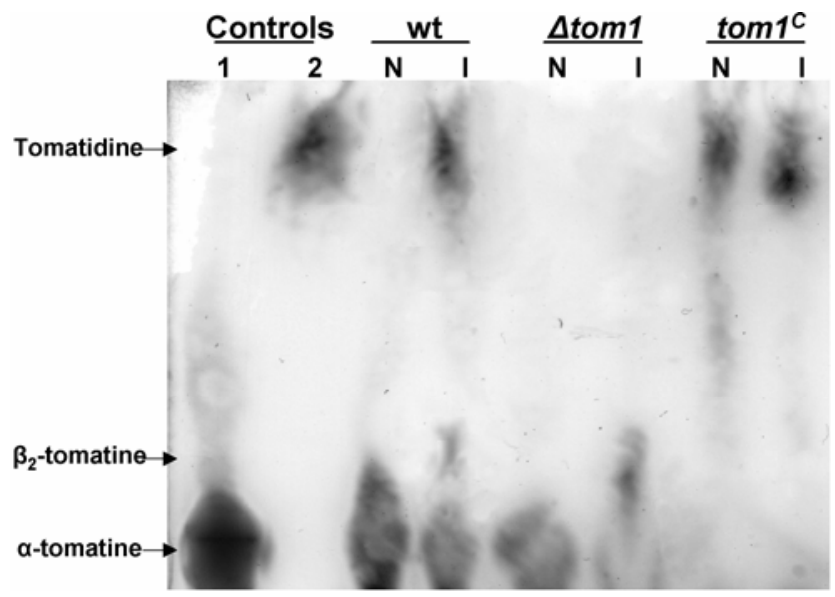

Fig. 5. Thin-layer chromatography analysis of tomatinase reaction products. Tomatine $(5 \mathrm{mM})$ was incubated overnight at room temperature with noninduced $(\mathrm{N})$ or induced (I) crude extracts from the wild type (wt), dis-

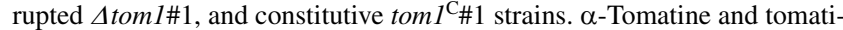
dine were loaded in lanes 1 and 2, respectively, and used as markers. The assay was repeated twice with similar results. Figure shows the results from a representative experiment. and $\Delta$ tom $1 \# 2$ colonies were always smaller. By contrast, this value was higher in the constitutive tom $l^{\mathrm{C}}$ transformant. Similar results were observed when strains were grown on 0.1 or 1 $\mathrm{mM} \alpha$-tomatine (data not shown).

\section{Pathotypic behavior of $\Delta$ tom 1 and $\operatorname{tom}^{\mathrm{C}}$ transformants on tomato.}

The role of the tom 1 gene in virulence of $F$. oxysporum $\mathrm{f}$. sp. lycopersici was determined by plant infection assays, performed by immersing the roots of 2-week-old tomato plants in microconidial suspensions of the wild-type strain, the deficient $\Delta t o m 1$ mutants, or the constitutive $\operatorname{tom} l^{\mathrm{C}}$ transformants. Plants were scored for vascular wilt symptoms at different time intervals after inoculation (Fig. 7). Severity of wilt symptoms in plants inoculated with the wild-type strain increased steadily throughout the experiment, and most of the plants were dead 20 days after inoculation. Plants inoculated with the $\Delta$ toml mutants showed a significant delay in symptom development compared with the wild-type strain, with most of the plants dead 25 days after inoculation. By contrast, $\operatorname{tom} l^{\mathrm{C}}$ transformants showed a significant increase in symptom development, because most of the plants were dead 15 days after inoculation (Fig. 7). Virulence experiments were performed three times with similar results.

\section{Identification of additional tomatinase genes in the $F$. oxysporum genome.}

The genome of $F$. oxysporum was explored in silico to further investigate the existence of additional tomatinase-encoding genes. No genes showing high similarity to toml (RoldanArjona et al. 1999) were found, whereas at least four genes encoding proteins with putative tomatinase activity were iden-

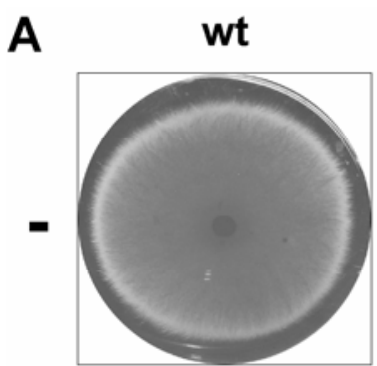

\section{$\Delta$ tom1\#1}
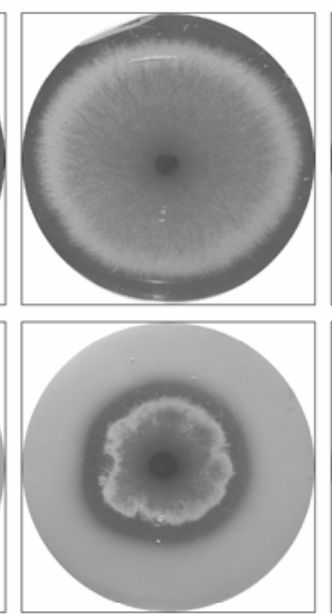

C

\section{$\Delta$ tom1\#2}
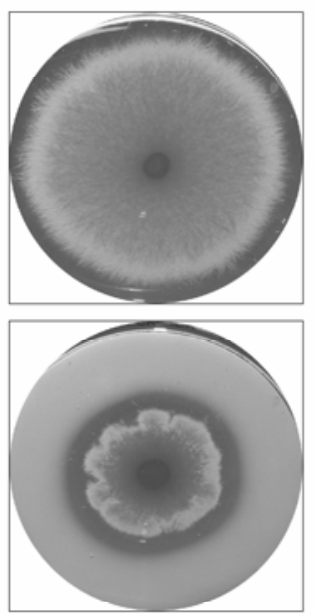

tom $1^{c}$
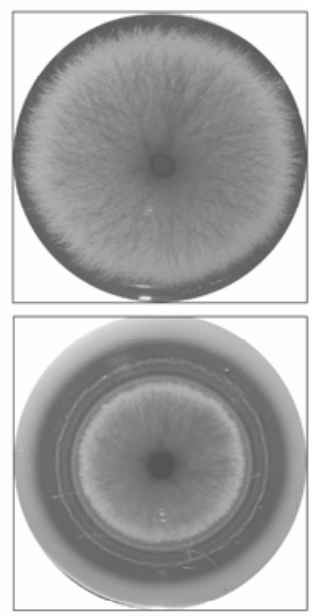

B

\begin{tabular}{|c|c|c|c|c|c|}
\hline Strain & $\mathrm{C}_{0}$ & $\mathrm{C}_{0.5}$ & $\mathbf{G l}(\%)$ & $\mathbf{H}_{0.5}$ & Ratio $\left(\mathbf{H}_{0,5} / \mathbf{C}_{0.5}\right)$ \\
\hline wt & $6,6 \pm 0,15$ & $4,4 \pm 0,15$ & $33,3 \pm 0,90$ & $4,5 \pm 0,05$ & $1,02 \pm 0,03$ \\
\hline$\Delta$ tom1\#1 & $6,8 \pm 0,30$ & $3,5 \pm 0,05$ & $48,5 \pm 3,05$ & $3,7 \pm 0,15$ & $1,05 \pm 0,03$ \\
\hline$\Delta$ tom1\#2 & $6,7 \pm 0,05$ & $3,6 \pm 0,01$ & $46,3 \pm 5,73$ & $3,8 \pm 0,20$ & $1,05 \pm 0,04$ \\
\hline tomf $^{\complement}$ & $6,9 \pm 0,25$ & $4,2 \pm 0,01$ & $39,1 \pm 2,90$ & $5,2 \pm 0,05$ & $1,23 \pm 0,01$ \\
\hline
\end{tabular}

Fig. 6. Effect of $\alpha$-tomatine on Fusarium oxysporum growth. A, Wild-type strain (wt), two disrupted transformants $\Delta$ tom $1 \# 1$ and $\Delta$ tom $1 \# 2$, and a constitutive transformant $\left(\right.$ tom $1^{\mathrm{C}}$ ) grown onto solid CA (casamino acid) medium in the absence (-) or presence $(+)$ of $0.5 \mathrm{mM} \alpha$-tomatine for 7 days. B, Diameter of the colonies in the presence of $0.5 \mathrm{mM} \alpha$-tomatine $(\mathrm{C})$ and of the surrounding halos $(\mathrm{H})$. $\mathbf{C}$, Measurement of the colony diameter (cm) in the absence of $\alpha$ tomatine $\left(\mathrm{C}_{0}\right)$, in the presence of $0.5 \mathrm{mM} \alpha$-tomatine $\left(\mathrm{C}_{0.5}\right)$, and the halos surrounding them $\left(\mathrm{H}_{0.5}\right)$. Growth inhibition $(\mathrm{GI})$ indicates the percentage of growth inhibition for each strain $\left(\mathrm{C}_{0.5}\right.$ values compared with $\left.\mathrm{C}_{0}\right)$. Ratio $\left(\mathrm{H}_{0.5} / \mathrm{C}_{0.5}\right)$ represents the relation between halo size and colony size observed for each strain in the presence of $\alpha$-tomatine. 
tified showing identity to the $\beta_{2}$-tomatinase from $S$. lycopersici (Durbin and Uchytil 1969; Osbourn et al. 1995; Sandrock et al. 1995). These genes were named tom 2 (FOXG_09849), tom3 (FOXG_02734), tom4 (FOXG_13018), and tom5 (FOXG_09125). The deduced amino acid sequences of these genes presented high identity degrees with family 3 glycosyl hydrolases: $51.8 \%$ identity between Tom 2 and $B$. cinerea sap 1 avenacinase, $53.5 \%$ between Tom 3 and $S$. lycopersici tomatinase, $50.0 \%$ identity between Tom 4 and $G$. graminis avenacinase, and $56.8 \%$ identity was found between Tom5 and $G$. graminis avenacinase. To establish the relationship between these proteins, the amino acid sequence from $F$. oxysporum tomatinases was aligned together with $S$. lycopersici $\beta_{2}$-tomatinase (Osbourn et al. 1995; Sandrock et al. 1995), G. graminis avenacinase (Bowyer et al. 1995), B. cinerea sapl avenacinase (Quidde et al. 1999), A. fumigatus glycosyl hydrolase family protein (Nierman et al. 2005), Streptomyces turgidiscabies tomatinase (Kers et al. 2005), and Clavibacter michiganensis tomatinase (Kaup et al. 2005) (data not shown). The resulting phylogenetic tree demonstrated that $F$. oxysporum tomatinases cluster into two different groups: Tom1 belongs to family 10

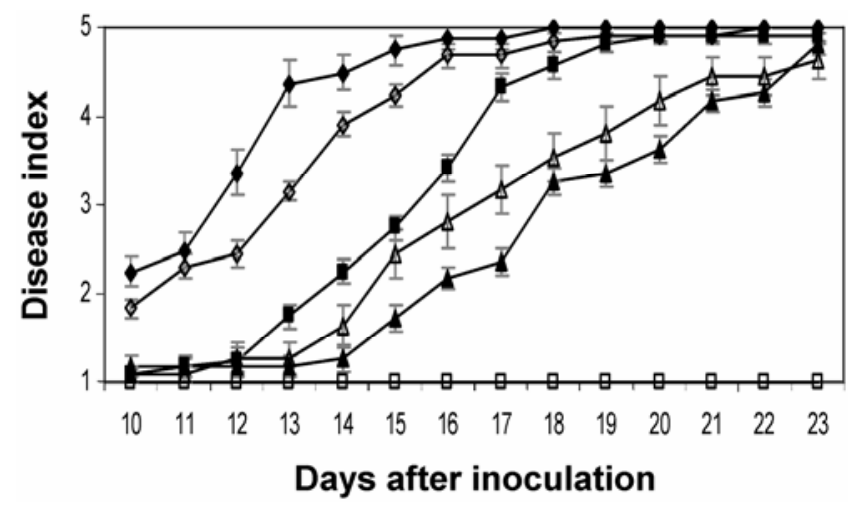

Fig. 7. Virulence of Fusarium oxysporum strains on tomato. Wilt disease incidence of the different strains on tomato plants (cv. Monika). Severity of disease symptoms was recorded at different times after inoculation, using an index ranging from 1 (healthy plant) to 5 (dead plant). Symbols refer to plants inoculated with the wild-type strain (ם), $\Delta$ tom 1\#1 transformant $(\Delta), \Delta$ tom $1 \# 2$ transformant $(\mathbf{\Delta})$, constitutive tom $1^{\mathrm{C}} \# 1$ transformant $(\diamond)$, constitutive tom $1^{\mathrm{C}} \# 8$ transformant $(\diamond)$, and the uninoculated control ( $\square$ ). Error bars indicate the standard deviations from 15 plants for each treatment. The data shown are from one representative experiment. glycosyl hydrolases, whereas Tom2, Tom3, Tom4, and Tom5 are members of family 3 glycosyl hydrolases (Fig. 8).

Reverse-transcription (RT)-PCR analysis using specific primers for each gene was performed in order to determine the expression pattern of tomatinase genes in the wild-type, $\Delta$ toml, and $\operatorname{tom}^{\mathrm{C}}$ strains grown in the absence or presence of $\alpha$-tomatine. In order to discriminate the amplicons obtained from genomic DNA, primer pairs were designed located within exons of the corresponding gene, except for the toml gene, which lacks intron sequences. The results indicated low expression levels of tom 2 and tom 5 in comparison with tom 1 gene, while expression of tom 3 and tom 4 was not detected in any condition (Fig. 9). Expression of tom 2 gene appeared to be induced by $\alpha$ -

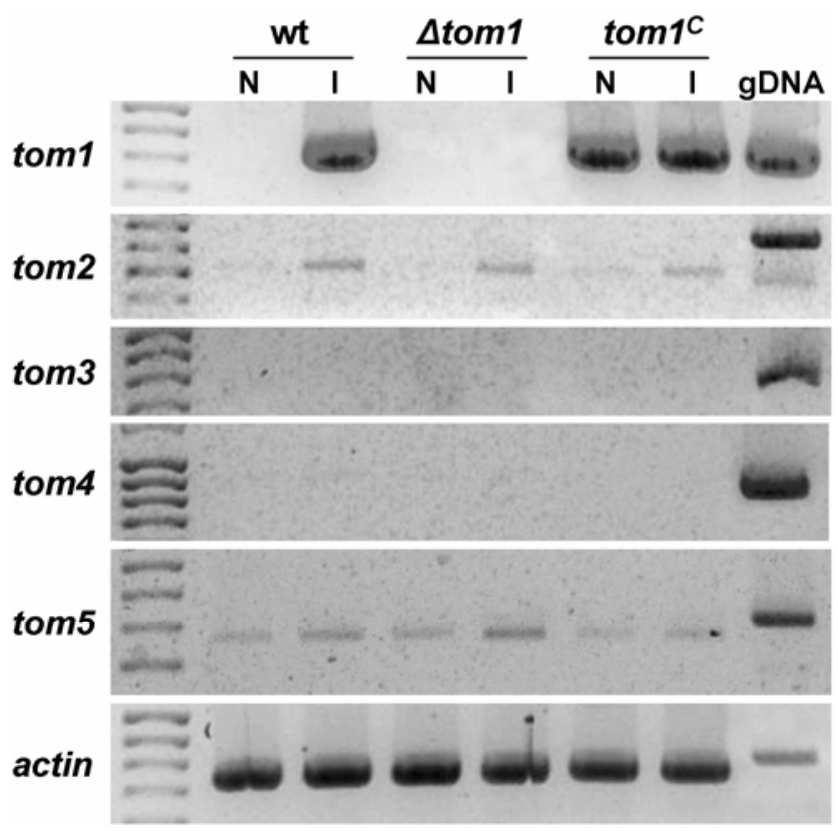

Fig. 9. Expression analysis of the tom 1, tom 2, and tom 5 genes by reversetranscription polymerase chain reaction (RT-PCR). Transcript levels of the predicted tomatinase genes tom 1, tom 2 , and tom 5 were determined by RTPCR in the wild-type strain (wt), disrupted $\Delta$ toml transformant, and a constitutive $\operatorname{tom}^{\mathrm{C}}$ mutant, grown in the absence $(\mathrm{N})$ or presence (I) of $\alpha$ tomatine. The actin gene was used as an internal control. Amplification of genomic DNA (gDNA) was used as positive PCR control.

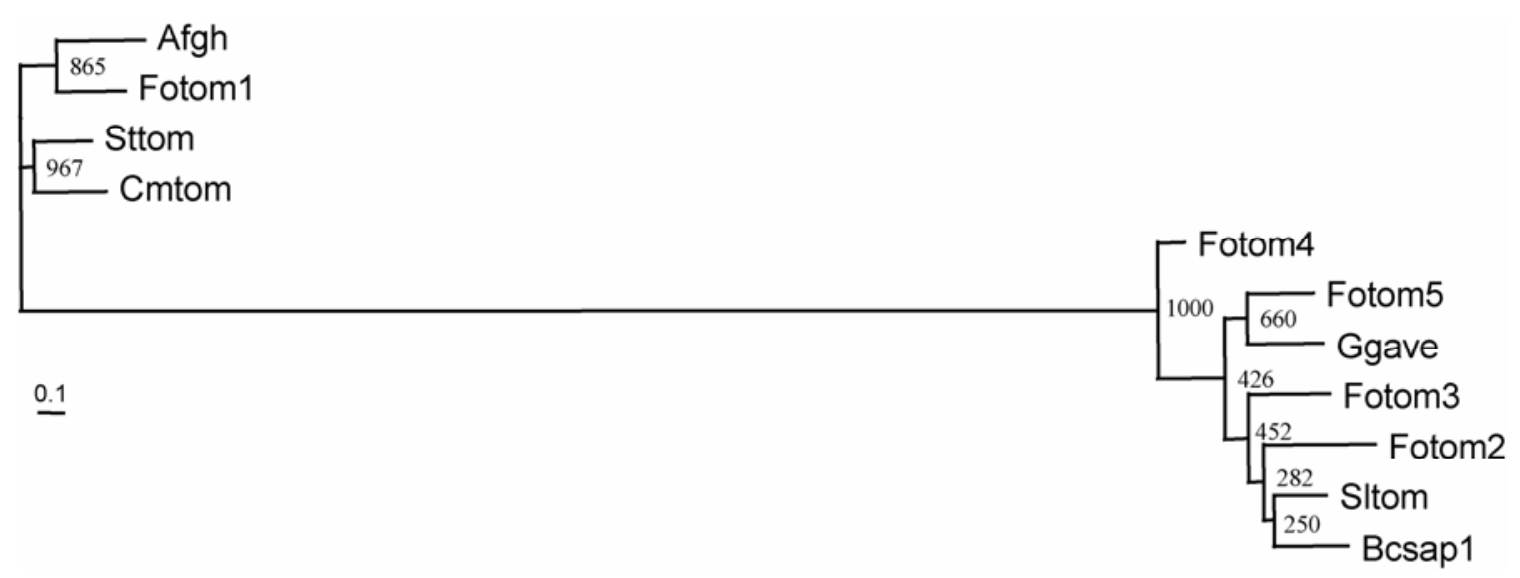

Fig. 8. Phylogenetic relationship between tomatinases from Fusarium oxysporum. Phylogram of a consensus phylogenetic tree obtained by maximum likelyhood method of F. oxysporum predicted tomatinases Tom1, Tom2, Tom3, Tom4, and Tom5; $\beta_{2}$-tomatinase from Septoria lycopersici (Sltom) (AAB08446); avenacinase from Gaeumannomyces graminis (Ggave) (AAA63146); tomatinase from Streptomyces turgidiscabies (Sttom) (AAW49296); tomatinase from Clavibacter michiganensis (Cmtom) (YP_001220829); a glycosyl hydrosase family protein from Aspergillus fumigatus (Afgh) (XP_751064); and avenacinase from Botrytis cinerea (Bcsap1) (CAB61489). Amino acid sequences were aligned using clustal W. Numbers at the branch points represent the bootstrap value based on 1,000 replicates. A scale bar indicating the genetic distance (substitutions per site) is shown. 
tomatine, whereas expression of tom5 was independent of the presence of the saponin in the culture medium. Inactivation or overexpression of the tom 1 gene did not alter the expression pattern of any of the genes. Expression of the tom 1 gene, also included in this analysis, showed a pattern similar to that in the Northern expression analysis.

\section{DISCUSSION}

The infection process of pathogenic fungi into plants involves a confrontation between two mechanisms: the attack of the pathogen and the plant defense response. Among the tomato plant defense weapons is the production of the saponin $\alpha$-tomatine, which is detoxified by a tomatinase enzyme secreted by the pathogen F. oxysporum f. sp. lycopersici (Lairini et al. 1996). This protein, encoded by the tom 1 gene, degrades the $\alpha$-tomatine, releasing tomatidine and the tetrasaccharide $\beta$-lycotretaose (Lairini et al. 1996; Roldan-Arjona et al. 1999).

Detoxification of plant saponins is considered to be a virulence determinant for pathogenic fungi and, therefore, several efforts have been made to establish the importance of saponinases in pathogenicity. Interestingly, an attempt to disrupt the toml gene in F. oxysporum resulted in the isolation of partial post-transcriptional silenced transformants with reduced pathogenicity on tomato plants (Ito et al. 2002). However, the authors could not conclude whether the toml gene played an essential role in pathogenicity. Here, we report the effects of the targeted disruption and overexpression of the tom 1 gene in F. oxysporum f. sp. lycopersici.

Northern analysis of the constitutive $\operatorname{tom} 1^{\mathrm{C}}$ strains reveals the presence of tom 1 transcripts under both inducing and noninducing conditions, confirming the overexpression of this gene. In agreement with this, tomatinase activity in $t o m 1^{\mathrm{C}}$ transformants was shown to be independent of the presence of $\alpha$-tomatine in the culture medium. By contrast, although tom 1 transcripts were absent in $\Delta$ toml mutants grown in the presence of the saponin, confirming tom 1 gene inactivation, a reduction of only $25 \%$ in the total tomatinase activity level was detected compared with the wild-type strain.

Further characterization of $\Delta$ tom 1 and $t o m 1^{\mathrm{C}}$ transformants revealed increased growth inhibition of the disrupted strains on solid media containing $\alpha$-tomatine, whereas no changes were observed in the constitutive transformants compared with the wild-type strain. These results indicate higher sensitivity to $\alpha$ tomatine displayed by the $\Delta$ tom 1 transformants due to the reduction in total tomatinase activity. However, comparable degradation halos surrounding the colonies were observed in the presence of high concentrations of the saponin for the $\Delta$ toml and the wild-type strain, whereas the halos in the constitutive tom $1^{\mathrm{C}}$ transformants were significantly larger, suggesting a stronger hydrolytic activity of $\alpha$-tomatine displayed by these transformants as a consequence of the overexpression of the toml gene.

Pathogenicity tests on tomato plants indicated that tom 1 disruption produces a delay in the progression of the disease symptoms compared with the wild-type strain, whereas the overexpression of the tom 1 gene results in a faster development of the symptoms. These results suggest that, although the toml gene is not an essential factor, it does contribute to full virulence of $F$. oxysporum on tomato plants.

Taken together, all these observations (the high tomatinase activity remaining in the $\Delta$ tom 1 strains, the similar degradation halo produced by the $\Delta$ tom 1 and the wild-type strains, and the reduced virulence of $\Delta$ toml) suggest that additional enzyme activities present in $F$. oxysporum might be contributing to the detoxification of the $\alpha$-tomatine, thus playing redundant functions. In silico analysis of the recently released complete ge- nome sequence of $F$. oxysporum revealed the existence of at least five independent tomatinase-encoding genes: the tom 1 gene which detoxifies the molecule into tomatidine and $\beta$-lycotetraose and belongs to family 10 of glycosyl hydrolases (Roldan-Arjona et al. 1999), and four additional genes with high identity to the avenacinase gene from G. graminis and the $\beta_{2}$-tomatinase gene from Septoria lycopersici, which belong to family 3 of glycosyl hydrolases (Henrissat and Bairoch 1993; Osbourn et al. 1995). We speculate that the proteins encoded by these four genes might be responsible for the remaining tomatinase activity and the degradation halos displayed by the $\Delta$ toml strains, in spite of the low expression levels of these genes. This hypothesis is supported by the results obtained from the TLC analysis of tomatine degradation products released by induced crude extracts from $\Delta$ tom 1 mutants where $\beta_{2}$-tomatine was the only detectable hydrolysis product, confirming the degradation of $\alpha$-tomatine by additional enzymes with a mechanism of action different from Tom1.

The existence of various genes encoding for tomatinase enzymes has been proposed previously in the tomato pathogen Colletotrichum coccodes (Sandrock and Vanetten 2001), where mutants lacking a functional copy of a $\beta_{2}$-tomatinase gene still were able to degrade $\alpha$-tomatine to tomatidine. In the fungal pathogen $B$. cinerea, at least three different saponin-degrading enzymatic activities have been described: sapl that detoxifies the avenacin, another one active on the digitonine and on the $\alpha$ tomatine, and a third one proposed as an avenacosidase (Quidde et al. 1999). The existence of five different tomatinase genes in the genome of $F$. oxysporum f. sp. lycopersici supports the idea that detoxification of $\alpha$-tomatine plays an important role during the infection of tomato plants. In S. lycopersici, mutants deficient in a $\beta_{2}$-tomatinase gene showed no changes in pathogenicity (Martin-Hernandez et al. 2000). The authors proposed that additional nondegradative mechanisms of resistance to $\alpha$-tomatine might exist, because no other hydrolysis products of the saponin were detected in the knockout mutants. Additionally, tomA genes, orthologous to $F$. oxysporum tom 1 , recently have been targeted inactivated in the tomato-pathogenic actinomycete Clavibacter michiganensis subsp. michiganensis and in the plant-pathogenic bacteria Streptomyces turgidiscabies, although the resulting mutants were not reduced in virulence (Kaup et al. 2005; Kers et al. 2005). By contrast, disruption of the avenacinase-encoding gene in the cereal-infecting fungus $G$. graminis var. avenae revealed that detoxification of avenacin A-1 is a determinant of host range (Bowyer et al. 1995; Osbourn et al. 1994). A similar role has been proposed for B. cinerea and Corynespora cassiicola tomatinases, where nonpathogenic strains lack the corresponding tomatinase-encoding genes (Oka et al. 2006; Quidde et al. 1998). On the other hand, heterologous expression of the Septoria lycopersici $\beta_{2}$-tomatinase gene in $N$. haematococca and Cladosporium fulvum strains unable to degrade $\alpha$-tomatine resulted in acquisition of the capacity to infect green tomato fruit and increase sporulation and infection extension on cotyledons, respectively (Melton et al. 1998; Sandrock and Vanetten 2001).

We conclude that, in F. oxysporum f. sp. lycopersici, detoxification of $\alpha$-tomatine plays an essential role during the infection of tomato plants, likely being the result of the combined action of different tomatinase activities. Therefore, simultaneous inactivation of the five tomatinase-encoding genes present in the genome of $F$. oxysporum would clarify this hypothesis.

\section{MATERIALS AND METHODS}

\section{Fungal isolates and culture conditions.}

F. oxysporum f. sp. lycopersici wild-type strain 4287 (race 2) was obtained from J. Tello, Universidad de Almería, Spain, and 
stored at $-80^{\circ} \mathrm{C}$ with $30 \%$ glycerol as a microconidial suspension. The pathotype of the strain was confirmed periodically by plant infection assays. For DNA extraction and microconidia production, cultures were grown in potato dextrose broth (Difco Laboratories, Detroit) at $28^{\circ} \mathrm{C}$ with shaking at $170 \mathrm{rpm}$ during 3 days as described previously (Di Pietro and Roncero 1998). For expression analysis, $5 \times 10^{8}$ microconidia from each strain were grown with shaking for $12 \mathrm{~h}$ at $28^{\circ} \mathrm{C}$ in $50 \mathrm{ml}$ of CA medium (CA at $10 \mathrm{~g} / \mathrm{liter}, 10 \mathrm{mM}$ ammonium sulfate, and yeast nitrogen base at $0.5 \mathrm{~g} /$ liter) before the addition of $\alpha$ tomatine at $30 \mu \mathrm{g} \mathrm{ml}^{-1}$ (Extrasynthèse, Genay, France), dis-

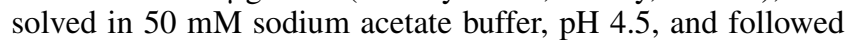
by additional incubation for $3 \mathrm{~h}$. The mycelia then were collected by filtration through nylon cloth (Monodur, mesh size $10 \mu \mathrm{m})$, washed with sterile water, and stored at $-80^{\circ} \mathrm{C}$. For tomatinase activity determination and TLC analysis, $2.5 \times 10^{6}$ microconidia were grown with shaking for $48 \mathrm{~h}$ at $28^{\circ} \mathrm{C}$ in 5 $\mathrm{ml}$ of CA medium containing $\alpha$-tomatine at $30 \mu \mathrm{g} \mathrm{ml}^{-1}$, previously dissolved in $50 \mathrm{mM}$ sodium acetate buffer, $\mathrm{pH} 4.5$. The cultures were filtered to separate mycelia and spores, and the supernatants were used to determine the tomatinase activity or the degradation products in TLC analysis.

\section{Nucleic acid isolation and analysis.}

Genomic DNA was extracted from fungal mycelia as described previously (Aljanabi and Martinez 1997). DNA was treated with the corresponding restriction enzyme and subjected to Southern analysis as described in standard protocols (Sambrook et al. 1989) with the nonisotopic digoxigenin-labeling kit (Roche Diagnostics SL). Probe labeling was carried out as previously reported (Di Pietro and Roncero 1998) using the primers tom $1-11 \mathrm{X}$ and tom $1-12 \mathrm{H}$ (Table 1) for probe a or tom1-X1 and tom1-5B (Table 1) for probe b. Total RNA was isolated from powdered mycelia using Tripure Isolation Reagent (Roche Diagnostics SL, Mannheim, Germany), according to the manufacturer's recommendations, except for all incubation steps that were developed on ice. Total RNA $(20 \mu \mathrm{g})$ was separated on a formaldehyde- $1 \%$ agarose gel and transferred to positively charged Nylon membranes (Roche Diagnostics SL) by capillarity. For quantification, the transferred RNA was stained for $5 \mathrm{~min}$ in $0.02 \%$ methylene blue in $0.3 \mathrm{M}$ sodium acetate, pH 5.2. After destaining in $20 \%$ ethanol, the filters were subjected to Northern analysis with the nonisotopic digoxigenin-labeling kit. Probe labeling was carried out as previously reported (Di Pietro and Roncero 1998) using the antisense primer tom1-16 (Table 1).

\section{Construction of plasmid vectors and fungal transformation.}

Gene replacement vector pDtom 1 was constructed as follows. A BamHI site was introduced at position 90 of the tom 1 coding region, using the overlapping method (Sambrook et al. 1989) with the primers tom1-9B and tom1-10B (Table 1), and the final product was cloned into pGEM-T (Promega, Madison, WI, U.S.A.). A 2.75-kb BamHI fragment containing the hygromycin B resistance gene under the control of an $A$. nidulans gpdA promoter (Punt et al. 1990) and $\operatorname{trpC}$ terminator (Mullaney et al. 1985) $\left(\mathrm{Hyg}^{\mathrm{r}}\right.$ cassette) was introduced at the new BamHI site in the tom 1 coding region. A linear fragment containing the interrupted tom 1 allele was amplified with primers tom 1-8 and tom 1-3 (Table 1) and used to transform protoplasts of $F$. oxysporum f. sp. lycopersici strain 4287, according to a protocol described previously (Di Pietro and Roncero 1998; Kistler and Benny 1988). $\mathrm{Hyg}^{\mathrm{r}}$ transformants routinely were subjected to two consecutive rounds of single sporing and stored as microconidia at $-80^{\circ} \mathrm{C}$. To generate a highly expressed allele of tom 1 , the coding region of the gene was fused to the strong constitutive $A$. nidulans gpdA promoter (Punt et al. 1990) as follows. A 1.16-kb fragment containing the complete open reading frame (ORF) of tom l was amplified by PCR from $F$. oxysporum genomic DNA, using primers tom1-X1 and tom1-3 (Table 1), and cloned into pGEM-T to generate plasmid ptomX. An XbaI-SpeI fragment containing the tom 1 ORF then was isolated from plasmid and cloned in frame with the gpdA promoter contained in plasmid pPgpdA. The complete fusion construct was amplified with primers gpdA-6H and tom1-3 (Table 1) and used to co-transform protoplasts of $F$. oxysporum f. sp. lycopersici strain 4287 together with a 3-kb PCR fragment containing the $\mathrm{Phleo}^{\mathrm{r}}$ amplified from the plasmid pAN8-1 with the primers gpd-2k and trpter2k (Table 1).

\section{Tomatinase activity assays.}

Proteins contained in supernatants obtained from induced cultures were concentrated by acetone precipitation and resuspended in sterile water. Tomatinase activity was measured spectrophotometrically at $525 \mathrm{~nm}$ with the DNS for determination of reducing sugars (Miller 1959). A 200- $\mu$ l volume from a reaction mixture containing $50 \mathrm{mM}$ sodium acetate buffer $(\mathrm{pH}$ 4.5), $\alpha$-tomatine at $2 \mathrm{mg} \mathrm{ml}^{-1}$, and $6.5 \mu \mathrm{g}$ of total protein was incubated overnight at room temperature. Reaction mixtures containing $\alpha$-tomatine-free buffer and protein extracts were used as control. After incubation, $200 \mu \mathrm{l}$ of 3,5-dinitrosalicylic acid solution was added, the mixture was boiled for $5 \mathrm{~min}$, and the final volume was brought to $1 \mathrm{ml}$ with water. Negative controls were prepared with protein extracts incubated in the absence of $\alpha$-tomatine.

\section{TLC analysis.}

Supernatants obtained from culture filtrates from the different strains grown in the absence or presence of $\alpha$-tomatine were incubated overnight with $5 \mathrm{mM} \alpha$-tomatine in $50 \mathrm{mM}$ sodium acetate buffer $(\mathrm{pH} 4.5)$ at room temperature. Incubation mixtures were vacuum-dried, resuspended into an appropriate volume of methanol, and separated on Silica Gel 25 TLC plates. The plates were developed in a solvent system consisting of acetic acid, ethyl acetate, methanol, and water (10:30:20:1, by volume). Spots were visualized after TLC plates were sprayed with $50 \%$ sulphuric acid and heated at $110^{\circ} \mathrm{C}$. The metabolites were identified by comparison with standards $(\alpha-$ tomatine and tomatidine, both $5 \mathrm{mM}$ ) which were treated in the same way as the incubation mixtures. $\alpha$-Tomatine appeared as a black spot near the origin, whereas tomatidine was localized as a dark green spot near the solvent front.

\section{$\alpha$-Tomatine sensitivity tests.}

For phenotypic analysis of colonies, fungal strains were grown on plates of $\mathrm{CA}$ medium containing agar at $20 \mathrm{~g} / \mathrm{liter}$, $\mathrm{pH} 7$, supplemented with different concentrations of $\alpha$-tomatine previously dissolved in $50 \mathrm{mM}$ sodium acetate buffer $(\mathrm{pH} 4.5)$. Aliquots of $2.5 \times 10^{6}$ freshly obtained microconidia were transferred to the center of each plate and incubated at $28^{\circ} \mathrm{C}$ for 7 days. Growth was examined by measurement of the colony diameter and the halo surrounding it.

\section{Pathogenicity assays.}

Infection of tomato plants was performed as reported previously (Di Pietro and Roncero 1998). Briefly, 2-week-old tomato seedlings were inoculated with $F$. oxysporum strains by immersing the roots in a suspension of $5 \times 10^{6}$ microconidia $\mathrm{ml}^{-1}$ for $30 \mathrm{~min}$, then planted in vermiculite and maintained in a growth chamber. Fifteen plants were used for each treatment. Severity of disease symptoms was recorded at different times after inoculation using an index ranging from 1 (healthy plant) 
to 5 (dead plant) (Huertas-Gonzalez et al. 1999). Virulence experiments were performed three times with similar results. Seed from tomato cv. Monika were kindly provided by Novartis Seeds.

\section{Identification of additional tomatinase genes in the $F$. oxysporum genome.}

Genes showing identity to tomatinases belonging to family 3 of $\beta$-glycosyl hydrolases were searched in the $F$. oxysporum genome database available at the Broad Institute database using the blast algorithm (Altschul et al. 1990). Clustal-W analysis was used to compare amino acid sequences of these genes.

\section{Phylogenetic analysis.}

Amino acid sequences were aligned with the CLUSTAL W algorithm (Thompson et al. 1994). The phyml v2.4.4 program (Guindon and Gascuel 2003) was used to perform a 1,000nonparametric bootstrap phylogenetic analysis of the resulting alignment with the maximum likelihood method after optimization of the settings by the modelgenerator v84 program (Keane et al. 2006). The analysis was performed using the WAG substitution model (Goldman and Whelan 2000) with a gamma distribution parameter $\alpha$ of 3.19. The phylogenetic relationships between sequences were depicted in a phylogenetic tree constructed using the TreeView v1.6.6 program (Page 1996).

\section{RT-PCR.}

Total RNA isolated from the different strains was treated with RNAse-free DNAse (Roche Diagnostics SL) and subjected to reverse transcription into cDNA with M-MLV reverse transcriptase (Invitrogen SA, San Diego, CA, U.S.A.) using a poli-dT antisense primer. The cDNA then was used for PCR amplification using the Expand High-Fidelity PCR System (Roche Diagnostics SL) with the primers tom2-1 and tom2-2 for tom 2, tom3-1 and tom3-2 for tom3, tom4-1 and tom4-2 for tom4, tom5-1 and tom5-2 for tom5, or tom1-11X and tom1$12 \mathrm{H}$ for toml (Table 1). The actin gene was used as the internal control using the primers act-1 and act-2 (Table 1).

\section{ACKNOWLEDGMENTS}

This research was supported by the Ministerio de Educación y Ciencia of Spain (BIO2004-0276) and Junta de Andalucía (CVI-138). Y. ParejaJamie was supported by a fellowship from Ministerio de Educación y Ciencia of Spain. We thank N. Rispail for valuable help with phylogenetic analysis, A. Di Pietro for helpful discussions, and E. Martínez for technical assistance (all from the University of Córdoba).

\section{LITERATURE CITED}

Aljanabi, S. M., and Martinez, I. 1997. Universal and rapid salt-extraction of high quality genomic DNA for PCR-based techniques. Nucleic Acids Res. 25:4692-4693.

Altschul, S. F., Gish, W., Miller, W., Myers, E. W., and Lipman, D. J. 1990. Basic local alignment search tool. J. Mol. Biol. 215:403-410.

Arneson, P. A., and Durbin, R. D. 1967a. Hydrolysis of tomatine by Septoria lycopersici: A detoxification mechanism. Phytopathology 57:1358-1360.

Arneson, P. A., and Durbin, R. D. 1967b. Studies on the mode of action on tomatine as a fungitoxic agent. Plant Physiol. 43:683-686.

Bouarab, K., Melton, R., Peart, J., Baulcombe, D., and Osbourn, A. 2002. A saponin-detoxifying enzyme mediates suppression of plant defences. Nature 418:889-892.

Bowyer, P., Clarke, B. R., Lunness, P., Daniels, M. J., and Osbourn, A. E. 1995. Host-range of a plant-pathogenic fungus determined by a saponin detoxifying enzyme. Science 267:371-374.

Defago, G., and Kern, H. 1983. Induction of Fusarium solani mutants insensitive to tomatine, their pathogenicity and aggressiveness to tomato fruits and pea-plants. Physiol. Plant Pathol. 22:29-37.

Di Pietro, A., and Roncero, M. I. G. 1998. Cloning, expression, and role in pathogenicity of $\mathrm{pg} 1$ encoding the major extracellular endopolygalactu- ronase of the vascular wilt pathogen Fusarium oxysporum. Mol. PlantMicrobe Interact. 11:91-98.

Di Pietro, A., Madrid, M. P., Caracuel, Z., Delgado-Jarana, J., and Roncero, M. I. G. 2003. Fusarium oxysporum: Exploring the molecular arsenal of a vascular wilt fungus. Mol. Plant Pathol. 4:315-325.

Durbin, R. D., and Uchytil, T. F. 1969. Purification and properties of a fungal $\beta$-glucosidase acting on $\alpha$-tomatine. Biochim. Biophys. Acta 191:176178.

Ford, J. E., McCance, D. J., and Drysdale, R. B. 1977. Detoxification of $\alpha$-tomatine by Fusarium oxysporum f. sp lycopersici. Phytochemistry 16:545-546.

Goldman, N., and Whelan, S. 2000. Statistical tests of gamma-distributed rate heterogeneity in models of sequence evolution in phylogenetics. Mol. Biol. Evol. 17:975-978.

Guindon, S., and Gascuel, O. 2003. A simple, fast, and accurate algorithm to estimate large phylogenies by maximum likelihood. Syst. Biol. 52:696-704.

Henrissat, B., and Bairoch, A. 1993. New families in the classification of glycosyl hydrolases based on amino acid sequence similarities. Biochem. J. 293:781-788.

Huertas-Gonzalez, M. D., Ruiz-Roldan, M. C., Di Pietro, A., and Roncero, M. I. G. 1999. Cross protection provides evidence for race-specific avirulence factors in Fusarium oxysporum. Physiol. Mol. Plant Pathol. 54:63-72.

Ito, S., Takahara, H., Kawaguchi, T., Tanaka, S., and Kameya-Iwaki, M. 2002. Post-transcriptional silencing of the tomatinase gene in Fusarium oxysporum f. sp lycopersici. J. Phytopathol. 150:474-480.

Ito, S., Eto, T., Tanaka, S., Yamauchi, N., Takahara, H., and Ikeda, T. 2004 Tomatidine and lycotetraose, hydrolysis products of $\alpha$-tomatine by Fusarium oxysporum tomatinase, suppress induced defense responses in tomato cells. FEBS (Fed. Eur. Biochem. Soc.) Lett. 571:31-34.

Ito, S., Nagata, A., Kai, T., Takahara, H., and Tanaka, S. 2005. Symptomless infection of tomato plants by tomatinase producing Fusarium oxysporum formae speciales nonpathogenic on tomato plants. Physiol. Mol. Plant Pathol. 66:183-191.

Kaup, O., Grafen, I., Zellermann, E. M., Eichenlaub, R., and Gartemann, K. H. 2005. Identification of a tomatinase in the tomato-pathogenic actinomycete Clavibacter michiganensis subsp michiganensis NCPPB382. Mol. Plant-Microbe Interact. 18:1090-1098.

Keane, T. M., Creevey, C. J., Pentony, M. M., Naughton, T. J., and McLnerney, J. O. 2006. Assessment of methods for amino acid matrix selection and their use on empirical data shows that ad hoc assumptions for choice of matrix are not justified. BMC Evol. Biol. 6:29.

Kers, J. A., Cameron, K. D., Joshi, M. V., Bukhalid, R. A., Morello, J. E., Wach, M. J., Gibson, D. M., and Loria, R. 2005. A large, mobile pathogenicity island confers plant pathogenicity on Streptomyces species. Mol. Microbiol. 55:1025-1033.

Keukens, E. A. J., Devrije, T., Fabrie, C., Demel, R. A., Jongen, W. M. F., and Dekruijff, B. 1992. Dual specificity of sterol-mediated glycoalkaloid induced membrane disruption. Biochim. Biophys. Acta 1110:127-136.

Keukens, E. A. J., deVrije, T., vandenBoom, C., deWaard, P., Plasman, H. H., Thiel, F., Chupin, V., Jongen, W. M. F., and deKruijff, B. 1995. Molecular basis of glycoalkaloid induced membrane disruption. Biochim. Biophys. Acta Biomembranes 1240:216-228.

Kistler, H. C., and Benny, U. K. 1988. Genetic-transformation of the fungal plant wilt pathogen, Fusarium oxysporum. Curr. Genet. 13:145149.

Lairini, K., and Ruiz-Rubio, M. 1998. Detoxification of $\alpha$-tomatine by Fusarium solani. Mycol. Res. 102:1375-1380.

Lairini, K., PerezEspinosa, A., Pineda, M., and RuizRubio, M. 1996. Purification and characterization of tomatinase from Fusarium oxysporum $\mathrm{f}$ sp lycopersici. Appl. Environ. Microbiol. 62:1604-1609.

Lairini, K., Perez-Espinosa, A., and Ruiz-Rubio, M. 1997. Tomatinase induction in formae speciales of Fusarium oxyporum non-pathogenic of tomato plants. Physiol. Mol. Plant Pathol. 50:37-52.

Martin-Hernandez, A. M., Dufresne, M., Hugouvieux, V., Melton, R., and Osbourn, A. 2000. Effects of targeted replacement of the tomatinase gene on the interaction of Septoria lycopersici with tomato plants. Mol. Plant-Microbe Interact. 13:1301-1311.

Melton, R. E., Flegg, L. M., Brown, J. K. M., Oliver, R. P., Daniels, M. J., and Osbourn, A. E. 1998. Heterologous expression of Septoria lycopersici tomatinase in Cladosporium fulvum: Effects on compatible and incompatible interactions with tomato seedlings. Mol. Plant-Microbe Interact. 11:228-236.

Miller, G. L. 1959. Use of dinitrosalicylic acid reagent for determination of reducing sugar. Anal. Chem. 31:426-428.

Morrissey, J. P., and Osbourn, A. E. 1999. Fungal resistance to plant antibiotics as a mechanism of pathogenesis. Microbiol. Mol. Biol. Rev. 63:708.

Mullaney, E. J., Hamer, J. E., Roberti, K. A., Yelton, M. M., and 
Timberlake, W. E. 1985. Primary structure of the trpc gene from Aspergillus nidulans. Mol. Gen. Genet. 199:37-45.

Nierman, W. C., Pain, A., Anderson, M. J., Wortman, J. R., Kim, H. S., Arroyo, J., Berriman, M., Abe, K., Archer, D. B., Bermejo, C., Bennett, J., Bowyer, P., Chen, D., Collins, M., Coulsen, R., Davies, R., Dyer, P. S., Farman, M., Fedorova, N., Fedorova, N., Feldblyum, T. V., Fischer, R., Fosker, N., Fraser, A., Garcia, J. L., Garcia, M. J., Goble, A., Goldman, G. H., Gomi, K., Griffith-Jones, S., Gwilliam, R., Haas, B., Haas, H., Harris, D., Horiuchi, H., Huang, J., Humphray, S., Jimenez, J., Keller, N., Khouri, H., Kitamoto, K., Kobayashi, T., Konzack, S., Kulkarni, R., Kumagai, T., Lafton, A., Latge, J. P., Li, W. X., Lord, A. Majoros, W. H., May, G. S., Miller, B. L., Mohamoud, Y., Molina, M., Monod, M., Mouyna, I., Mulligan, S., Murphy, L., O’Neil, S., Paulsen, I., Penalva, M. A., Pertea, M., Price, C., Pritchard, B. L., Quail, M. A., Rabbinowitsch, E., Rawlins, N., Rajandream, M. A., Reichard, U., Renauld, H., Robson, G. D., de Cordoba, S. R., Rodriguez-Pena, J. M., Ronning, C. M., Rutter, S., Salzberg, S. L., Sanchez, M., SanchezFerrero, J. C., Saunders, D., Seeger, K., Squares, R., Squares, S., Takeuchi, M., Tekaia, F., Turner, G., de Aldana, C. R. V., Weidman, J., White, O., Woodward, J., Yu, J. H., Fraser, C., Galagan, J. E., Asai, K., Machida, M., Hall, N., Barrell, B., and Denning, D. W. 2005. Genomic sequence of the pathogenic and allergenic filamentous fungus Aspergillus fumigatus. Nature 438:1151-1156.

Oka, K., Okubo, A., Kodama, M., and Otani, H. 2006. Detoxification of $\alpha-$ tomatine by tomato pathogens Alternaria alternata tomato pathotype and Corynespora cassiicola and its role in infection. J. Gen. Plant Pathol. 72:152-158.

Osbourn, A., Bowyer, P., Lunness, P., Clarke, B., and Daniels, M. 1995. Fungal pathogens of oat roots and tomato leaves employ closely related enzymes to detoxify different host plant saponins. Mol. Plant-Microbe Interact. 8:971-978

Osbourn, A. E. 1996. Preformed antimicrobial compounds and plant defense against fungal attack. Plant Cell 8:1821-1831.

Osbourn, A. E., Clarke, B. R., Lunness, P., Scott, P. R., and Daniels, M. J 1994. An oat species lacking avenacin is susceptible to infection by Gaeumannomyces graminis var tritici. Physiol. Mol. Plant Pathol. 45:457-467.

Page, R. D. M. 1996. TreeView: An application to display phylogenetic trees on personal computers. Comput. Appl. Biosci. 12:357-358.

Punt, P. J., Dingemanse, M. A., Kuyvenhoven, A., Soede, R. D. M., Pouwels, P. H., and Vandenhondel, C. 1990. Functional elements in the promoter region of the Aspergillus nidulans gpda gene encoding glyceraldehyde-3-phosphate dehydrogenase. Gene 93:101-109.

Quidde, T., Osbourn, A. E., and Tudzynski, P. 1998. Detoxification of $\alpha$ tomatine by Botrytis cinerea. Physiol. Mol. Plant Pathol. 52:151-165.

Quidde, T., Buttner, P., and Tudzynski, P. 1999. Evidence for three different specific saponin-detoxifying activities in Botrytis cinerea and cloning and functional analysis of a gene coding for a putative avenacinase. Eur. J. Plant Pathol. 105:273-283.

Roddick, J. G. 1977. Subcellular localization of steroidal glycoalkaloids in vegetative organs of Lycopersicon esculentum and Solanum tuberosum. Phytochemistry 16:805-807.
Roddick, J. G. 1979. Complex formation between solanaceous steroidal glycoalkaloids and free sterols in vitro. Phytochemistry 18:14671470.

Roldan-Arjona, T., Perez-Espinosa, A., and Ruiz-Rubio, M. 1999. Tomatinase from Fusarium oxysporum f. sp lycopersici defines a new class of saponinases. Mol. Plant-Microbe Interact. 12:852-861.

Sambrook, R. W., Fritsch, E. F., and Maniatis, T. 1989. Molecular Cloning: A Laboratory Manual. Cold Spring Harbor Laboratory Press, Cold Spring Harbor, NY, U.S.A.

Sandrock, R. W., and VanEtten, H. D. 1998. Fungal sensitivity to and enzymatic degradation of the phytoanticipin $\alpha$-tomatine. Phytopathology $88: 137-143$.

Sandrock, R. W., and Vanetten, H. D. 2001. The relevance of tomatinase activity in pathogens of tomato: Disruption of the $\beta_{2}$-tomatinase gene in Colletotrichum coccodes and Septoria lycopersici and heterologous expression of the Septoria lycopersici $\beta_{2}$-tomatinase in Nectria haematococca, a pathogen of tomato fruit. Physiol. Mol. Plant Pathol. 58:159171.

Sandrock, R. W., DellaPenna, D., and VanEtten, H. D. 1995. Purification and characterization of $\beta_{2}$-tomatinase, an enzyme involved in the degradation of $\alpha$-tomatine and isolation of the gene encoding $\beta_{2}$ tomatinase from Septoria lycopersici. Mol. Plant-Microbe Interact. 8:960-970.

Schönbeck, F., and Schlösser, E. 1976. Preformed substances as potential protectants. Pages 653-678 in: Physiological Plant Pathology. R. Heitefus and P. H. Williams, eds. Springer-Verlag, Berlin.

Steel, C. C., and Drysdale, R. B. 1988. Electrolyte leakage from plant and fungal tissues and disruption of liposome membranes by $\alpha$-tomatine. Phytochemistry 27:1025-1030.

Suleman, P., Tohamy, A. M., Saleh, A. A., Madkour, M. A., and Straney, D. C. 1996. Variation in sensitivity to tomatine and rishitin among isolates of Fusarium oxysporum $\mathrm{f}$ sp lycopersici, and strains not pathogenic on tomato. Physiol. Mol. Plant Pathol. 48:131-144.

Thompson, J. D., Higgins, D. G., and Gibson, T. J. 1994. Clustal-W-improving the sensitivity of progressive multiple sequence alignment through sequence weighting, position-specific gap penalties and weight matrix choice. Nucleic Acids Res. 22:4673-4680.

Vanetten, H. D., Mansfield, J. W., Bailey, J. A., and Farmer, E. E. 1994. 2 Classes of plant antibiotics-phytoalexins versus phytoanticipins. Plant Cell 6:1191-1192.

Vanetten, H., Temporini, E., and Wasmann, C. 2001. Phytoalexin (and phytoanticipin) tolerance as a virulence trait: Why is it not required by all pathogens? Physiol. Mol. Plant Pathol. 59:83-93.

Weltring, K. M., Wessels, J., and Pauli, G. F. 1998. Metabolism of the tomato saponin $\alpha$-tomatine by Gibberella pulicaris. Phytochemistry 48:1321-1328

\section{AUTHOR-RECOMMENDED INTERNET RESOURCE}

Broad Institute $F$. oxysporum genome database: www.broad.mit.edu/annotation/genome/fusarium_group/ 